\title{
Research on the Chinese Nongovernment Organizations Participating in Rural Governance: Functional Localization, Dilemma and Countermeasure
}

\author{
Shaogang Liao, Ying Pan \\ School of Public Finance and Public Administration, Jiangxi University of Finance and Economics, Nanchang, China
}

Email address:

liaoshaogang@163.com (S. Liao)

To cite this article:

Shaogang Liao, Ying Pan. Research on the Chinese Nongovernment Organizations Participating in Rural Governance: Functional Localization, Dilemma and Countermeasure. International Journal of Economic Behavior and Organization. Vol. 3, No. 2, 2015, pp. 18-22.

doi: $10.11648 /$ j.ijebo.20150302.11

\begin{abstract}
As china is a big agricultural country, the modernization of rural governance is the key point of modernization of national governance. The important characteristic of modernization of governance is that the nongovernment organizations participation in the governance actively. At the present, Chinese rural nongovernment organizations develop very quickly. However, there are still some dilemmas of those organizations participating in rural governance. It needs the governments actively lead the nongovernment organizations to participate in governance and establish the virtuous circle of it. At the same time, the nongovernment organizations need to get rid of the self obstacles and lift the ability of participating in governance.
\end{abstract}

Keywords: Non-Governmental Organizations, Rural Governance, Cooperate Altogether to Govern

\section{Introduction}

At the present, improving the modernization of the national governance system and ability is looked as Chinese key goal of national development and comprehensively deepening the reform. As china is a big agricultural country, the modernization of rural governance is the key point of modernization of national governance. The important characteristic of modernization of governance is diversification of governance main body, which is one of the main differences between the modern governance and traditional governance. One of the important expressions of the diversification of governance main body is that the nongovernment organizations actively participating in governance. Now, many Chinese rural areas are facing the governance crisis, which the underground church and black evil force appear, contorting the rural governance order. On the other hand, the farmers have rare political participation and village self-governance. In order to face these challenges and realize the fine rural governance order, the nongovernment organizations are needed to participate in the rural governance and promote the modernization of rural governance.

In the recent years, along with the reform of the community management system, all kinds of nongovernment organizations developed very quickly. The growth rate of the number of registered nongovernment organizations had continuously exceeded that of GDP, reached to $10 \%--15 \%$. The unregistered nongovernment organizations' number are much larger, which are about several million. Among those nongovernment organizations, the development of the rural nongovernment organizations is the most active. According to the statistics of Civil Administration Departments, taking the Chinese social communities as the example, the number of the agricultural and rural nongovernment organizations was 58825 in the end of 2013, $20 \%$ of the whole number. Some scholars estimated that including all kinds of unregistered nongovernment organizations, the number of Chinese rural nongovernment organizations exceeded 2 million, which included economic cooperation organizations, support groups, for example: the Professional Economic Associations, the Senior Citizen Association, Temple Fair, Lantern Fair, Environmental Protection Association, etc. Among the rural nongovernment organizations, mainly those small size interest and support groups, most of them were not registered in Civil Administration Departments. Among these organizations, the agricultural professional associations had the largest number and grown fastest. The production, circulation of agricultural and sideline products and the professional economic activities, 
such as relative sic-tech population, infrastructure construction are the ties of the agricultural professional associations. The associations are the non-profit membership organizations, spontaneously organized by some relative practitioners, such as: Farmers' Professional Cooperative, the Aquaculture Association, the Farmers Science Association, etc.

\section{The Functional Localization of the Chinese Non-government Organizations Participating In the Rural Governance}

The function of the nongovernment organizations participating in the rural governance includes the expression and synthesis of farmers' interests, supply of rural public goods and social capital accumulation of rural areas.

\subsection{The Expression and Synthesis of Farmers' Interests}

At the present, the rural areas are in the transition period of urbanization. Because of the air pollution, contradiction between labor and capital, demolition and clashes among villages, the mass disturbance happens frequently, led by the conflict of interests. Under new situation, the interest's differentiation is obvious and the interest relations are complicated. The governments need to fully consider the interest needs of every class and group in countries when carry out the policies. The farmers pay high costs when express their points to the governments. And they seldom get the attention of local governments, hard to get the effects. "the structure of association interest groups makes the leaders to understand the points of its members and mobilizes they to positively active, supporting some special policies."The nongovernment organizations have the natural advantages on expressing famers' interests, which are the association organizations from bottom to top and more close to people. They express rationally to the society and governments according to the organizations' interests. The continuously growing rural nongovernment organizations organize the farmers again through various forms and play an important role on improving the farms' expression, coordinating the social groups' interests, promoting the social harmony. The rural nongovernment organizations use the flattening organization structure. So the internal members are relatively equal and internal governance is relatively democratic. The development of the rural nongovernment organizations improves the farmers 'qualities and pushes forward the democratic politic process.

\subsection{Participating in the Supply of Rural Public Goods}

Along with of social economic development of countries, on one hand, the total needs of farmers to the public goods continuously increase. One the other hand, the farmers 'needs to the public good are increasingly diversified. In the supply of public goods, markets and governments have their own defects. When the markets supply the rural public goods, it has a shortage supply and hard to ensure the quality. The public goods supplied by the governments are often single, only satisfying the basic public needs of farmers. The rural public cultural services are inefficient, ignoring the famers' practical needs because of the lack of competition. For example, some scholars found that the lack and excess of public cultural services exit together. Some public cultural services are supplied by some basic level governments in order to reflect the governors 'achievements in their official career and help for their promotion, not for the farmers' cultural needs. At the present, the county governments have the limited finical resources. The officials would like to invest the construction in small towns, lack of interests on supply of public goods. The nongovernment organizations participating in the supply of rural public products can make up the defects of markets and governments. The nongovernment organizations compete with each other and have their own professional advantages, which would save the costs and improve the supply efficiency. The nongovernment organizations can satisfy the farmers 'diversified demand. The famers who have the same public needs and interests can spontaneously organize and cooperate to supply the public products needed by the internal members. The nongovernment organizations have the small scale and are efficient and flexible. For having the wide social relations, they have the relative advantages of saving the transaction costs in the fields of charity, environment protection, protecting the vulnerable groups, education, culture, business and technologic services. The nongovernments organizations participating in the supply of rural public goods can improve the rural public goods supply, lift the rural public participation and restrain the local bureaucratize. In the Third Plenary Session of the Party's Central Committee put forward the ideas of innovates the social managing system and stimulating the social organization's energy. The public services and some issues, fitting for being supplied by the social organizations need to be undertaken by the social organizations. The methods which the nongovernment organizations participating in the rural public goods are varied, such as producing directly, purchasing from the markets and providing to the public, selling the professional services to the governments and cooperating with the governments. Nowadays, the scope and fields of public goods, supplied by the cooperation between each level governments and nongovernment organizations through contracts, are expanded continuously. The nongovernment organizations have become the important cooperative partners of governments. The public goods and services supplied by the nongovernment organizations in counties include social services, animal protection, community development, health care, primary schools and high schools run by the local people, employment services, preventing and fighting natural calamities and supporting the poorer, etc.

\subsection{Social Capital Accumulation of Rural Areas}

Social capital accumulation of rural areas means the features of social organizations such as trusts, rules and 
networks. They could improve the social efficiency through the cooperative behaviors. The farmers' personal relationship networks and the informal system in the rural areas are the main parts of the rural social capital accumulation. Through measuring the farmers' participation in the public affairs, famers' sense of village belonging, the cooperation and trust between farmers, the situation of social capital of some specific areas can be measured. After the household contract responsibility system was carried out, the economic cooperation behaviors had been reducing. After the 1980s, along with the development of market economy and expanded scope of farmers' communication, the rural social relations based on the genetic relationships and geographical relationships was getting weak. The traditional social customs and values came under attack. The relations between famers became more indifferent, sense of belonging getting weak, mutual assistance behaviors between farmers decreasing and trusts crisis between people appearing. The social capital can overcome the difficulties of collective activities, raise the public participation's efficiency, and improve the governments' performance, promote the harmony of rural society. During the rural social governance, the social capital can provide various social supports to the farmers, standard people's behaviors, improve the trust between people and reduce the risks of rural business, decrease the business costs. Social capital could provide the system rules and spiritual support to the rural social governance, enhance the rally power of rural society, and integrate the rural social order. In a word, the modern rural social governance provides the fine environment for rebuilt of rural social capital. Cohesion type, bridged type and connection type social capital investment could form the internal optimum interaction and strengthen the trusts and cooperation between the members of the nongovernment organizations and stakeholders. The continuous interaction between the multiple interests mainstay in the rural social governance provides the fields of communication for enhancing the social trusts, rebuilding the social orders and social relation networks. Various agricultural professional associations, agricultural cooperation and famer associations etc. the rural nongovernment organizations have promoted the farmers' participation in the rural social governance, speed up the capital accumulation of rural society.

\section{The Dilemmas of Chinese Non-government Organizations Participating in the Rural Governance}

Although the nongovernment organizations have a key role in promoting the modernization of rural governance, the level of nongovernment organizations participating in the rural governance is relatively lower in the present practice. Because the development of the rural nongovernment organizations is imbalance the poor development and insufficient engagement of civil nongovernment organizations exist. There are less civil nongovernment organizations in villages, most of which are the affiliated organizations of village councils. The organizations participate in the governance according to top-down management method, contrary to the modern social governance system. The nongovernment organizations participating in the rural governance is not so active and the result is not ideal. So, the Chinese nongovernment organizations participating in the rural governance is facing many difficulties.

\subsection{The Dilemma of Legitimacy}

The scale of rural nongovernment organizations is small and the capital of it is limited. It is hard to achieve the standard of registration and hard to find the competent departments. Because of the constraint of laws, most nongovernment organizations wouldn't like to register so as to these organizations aren't recognized by the laws. Outside the law, their lawful rights are still less than guatanteed.And the legality of rural nongovernment organizations is very serious as well. In the traditional rural society, the governance subject is single. The modern governance system is the multiple subjects' co-governance, which is a breakthrough in traditional governance model. The nongovernment organizations participating in the rural governance need the public authority as the base. It would subject to a boycott of traditional authorities and also be a challenge to approval of authorities. Although some county governments support the development of rural nongovernment organizations, the governments look the organizations as their affiliated organizations. Once the both sides clash with each other, the legitimacy of nongovernment organizations would be nonexistent. Some farmers don't approve of the nongovernment organizations. On one hand, they are influenced by the traditional views. On the other hand, they have low confidence to the nongovernment organizations. Because of the existence of legitimacy issues, the nongovernment organizations are lack of power on participating in the rural governance. It is a big trouble faced at the present.

\subsection{The Scarce Capacity of Participating in the Rural Governance}

The nongovernment organizations participating in the rural governance need the social resources as the support. Many rural nongovernment organizations cannot run normally because of the lack of enough money. However, those nongovernment organizations which gain the government funds would rely on the governments, for the governments give the money to them. The nongovernment organizations gradually lost the initiative and become an extension of the governments. The rural nongovernment organizations become the activity centers of retired people and part-time duty personnel. There is very few internal full-time staff. Their comprehensive quality is not very high as well, lac of professional knowledge and innovation ability. Except the nongovernment organizations have the limited governance ability because of the lack of social resources, most 
nongovernment organizations have some problems on management, operation, for example, the nonstandard management system, the unscientific organization, the lagging self-building. Nowadays, the internal control system of the most Chinese nongovernment organizations exist flaw. No special decision-making organs are set up. At the same time, the relevant rule and systems of democratic decision-making are not set up. There aren't any perfect finical supervision systems. The nongovernment organizations' lack of self management must influence their own administrative ability. At the same time, it will influence their participation in the rural governance.

\subsection{Lack of Governance Platform and Institution Guarantee}

In the rural governance, the nongovernment organizations accept the invitation of the government to participate in the governance only with the passive attitude. Their legal interests are difficulties to be guaranteed. When the wills of the nongovernment organizations disagree with the basic-level governments, the basic-level governments will find a way to prevent the substantial participation of the nongovernment organizations. Although the basic-level governments activate build the rural diverse management structure with an open mind, the effect of nongovernment organizations participating in governance is not satisfied because the traditional governance authorities such as the nongovernment organizations, basic-level governments, and the villager autonomy organs are lack of mature cooperative system.

\section{The Countermeasure of Promoting the Nongovernment Organizations Participating in the Rural Governance}

In order to improve the nongovernment organizations participating in the rural governance, we need to take the following measures:

\subsection{Solve the Legality of the Nongovernment Organizations}

At the present, the Chinese nongovernment organizations are numerous. However, the proportion of the organizations registered and approved by the laws is small. It extremely affects the nongovernment organizations to participate in the rural governance and prevent them to play the superiority in the governance. On the contrary, It would cause the confusion. The legality of the nongovernment organizations lies in the farmers' approval to the various nongovernment organizations. If the famers distrust the nongovernment organizations, the organizations would not be approved in governance although their legitimacy in form。

At first, the governments should increase the registration flexibility of nongovernment organizations and help that existing nongovernment organization who still hasn't got the legal identity to finish registration. Second, the governments should set up the supervision departments scientifically to supervise the nongovernment organizations. At the same time, formulate corresponding laws and regulations to clear the responsibilities which the supervision departments should undertake in the form of laws and clear their business areas. Third, it needs to change the past restricting competitive behaviors and encourage competition. The rule should be abolished, which two or more nongovernment organizations who have the similar business areas can't exit in the same administrative region. The competition mechanisms should be introduced to the nongovernment organizations to form good competition. In the end, the governmental departments should attach importance to the process management of nongovernment organizations. That is to say, to supervise the operational process of nongovernment organizations and look the relevant operating programs of nongovernment organizations as the focus of regulatory efforts. Once find illegal behaviors, punish without leniency.

\subsection{Improve the Self-Management Level}

First, a sound management system should be set up within the nongovernment organizations, which is the internal management system. The scientific and reasonable internal management system can promote the insiders of the nongovernment organizations to realize the self-managements and self development, which is the corn of internal operating mechanism. At the same time, based on the internal management mechanism, some relevant policy-making organizations and democratic decision-making system should be set up within the nongovernment organizations. At the present, viewed from the development of the nongovernment organizations' institutional improvement, they have made a try to uniform rules system within limits. However, these rules and regulations seem a little general and have not been refined, such as member management, internal construction, as so on. In perfect process, the nongovernment organizations should pay more attention to the famous experts' opinions and suggestions. The nongovernment should make the established rules and regulations feasible in practice and have practical meaning. Seond, the external supervision system should be further improved. The nongovernment organizations not only need the internal supervision, but also accept the supervision from the public. Thus, this would further normalize the nongovernment organization's behavior of participating in the rural governance, in order to ensure the organizations to keep the non-profit character and gradually improve abilities of supplying the public goods and service to the society.

\subsection{Form the Cooperative and Common-Governing Benign Interactions between the Governmental Organizations and Nongovernment Organizations}

In the modern governance system, the county governments transfer part of social management and social service functions to markets and nongovernment organizations. The nongovernment organizations actively take part in the rural governance through taking on these functions. Through taking on these functions, the nongovernment organizations explore 
the area of activities, improve the service ability, and realize their own self-worth, which is helpful to build the virtuous circle of the nongovernment organizations participating in the social governance. Meanwhile, through leading the nongovernment organizations to participating in the rural governance, it is helpful to reduce the governments' burden, push for the system reform, smoothly realize the government transformation and eventually realize the good governance. Viewed from the point of perfecting the nongovernment organizations' own development and promote the modernization of rural social governance, it needs to create social governance model, launch the pilot projects of nongovernment organizations actively participating in the social services. It would make the nongovernment organizations become the key role of rural social governance. Meanwhile, it needs to strengthen the standard management and service, clear the nongovernment organizations' function position and operational mechanism in the every field of politics, economy and culture.

\section{References}

[1] Yu Keping. 2014. Promote National Governance System and Modern Governance Capacity .Frontline 1:13

[2] Ministry of Civil Affairs, Statistical Bulletin of Social Service Development in 2013 issued by Ministry of Civil Affairs.http://www.mca.gov.cn/article/zwgk/mzyw/201406/20 140600654488
[3] Liu Yiqiang.2009.Build the Rural Social Organization Mechanism Guided by the Social Self-government Functions. Southeast Academic Research1:79-85

[4] Hou Zengzhou, Wang Shoubao, 2011.The Main Transaction Costs in the Supply of Public Goods and Comparative Advantage of NGO. Study and Explore2:158-161

[5] Zhang Jinsong, Xu Tiantian.2012. The Theory of the Nongovernment Organizations Undertaking the Governmental Functions. The New Horizons 4:71-76

[6] Gabrielle A Almond Bingham Powel, Translated by Cao Peiling .2007.Compatative Politics. Oriental Press: 215

[7] Putnam. Translated by Wang Lei, Lai Hairong.2001. Making Democracy Work. Jiangxi People's Publishing House: 195

[8] Li Jia.2012.The Innovation of Rural Public Cultural Products Supply Model-----Based on the Perspective of Building Order and Combining with the Spontaneous Order.Changbai Journa,5:147-151

[9] Wan Shengxin, Li Shiping.2013. Research of the Social Capital Influence on the Nongovernment Organization Development----Farmer Warder- Consumer Association as an Example. Theoretical Discussion5:165--167

[10] Xie Haiding. 2014. The Legitimacy Dilemma of Chinese Civil Organizations. Chinese Journal of Law2:17-34

[11] Jiang Jiwei. 2014. Social organization development predicament under the view of the Externality of organizations. The Sociology of Science 2:104-107 